\title{
The Pollution and Health Risk Assessment of Toxic Organics in Surface Water of Beijing
}

\section{Sun Changhong ${ }^{1,2}$, Fang Yaoyao' ${ }^{2}$, Ling Wencui ${ }^{2}$, Sun Xueting ${ }^{2}$, Fan Yumei $^{2}$, , Li Huanli ${ }^{2}$ Li Weiwei ${ }^{3}$, Liu Guizhong, ${ }^{2, *}$}

\author{
${ }^{1}$ Tianjing University, Tianjing 300072, China: sunchanghong@,cee.cn \\ ${ }^{2}$ Beijing Municipal Research Institute of Environmental Protection, Beijing 100037, \\ China: Fangyaoyao@cee.cn; Lingwencui@cee.cn; Sunxueting@,cee.cn; \\ Fanyumei@cee.cn;Liuguizhong@,cee.cn; Lihuanli@,cee.cn; \\ ${ }^{3}$ College of Urban and Environmental Sciences, Peking University, Beijing 100871, \\ China: Liwenwei@cee.cn;
}

*corresponding author: Liu guizhong (1615171@qq.com)

Tel.: +0086- 13693388370; Fax: +0086-10-88362155

\begin{abstract}
:
The study of the distribution and health risk assessment is meaningful to provide basic data for environmental management. To investigate the pollution of potential toxic organics and their health risk to human beings, water samples were collected at 7 sites of main surface water of Beijing during wet and dry seasons respectively. The targeted 92 organics were detected, including phthalates (PAEs), volatile organic compounds (VOCs), polycyclic aromatic hydrocarbons (PAHs) and phenols. The results showed that: there were 56 organics detected out, and the number ratios of detected compounds to the total compounds of the same kind increased as the following: VOCs, phthalates, phenols, PAHs. 8 VOCs were detected in wet season, and 3 in dry season. The concentration of 2,2-Dichloropropane was highest as $10.62 \mathrm{ug} / \mathrm{L}$, while the concentrations of other VOCs were below $5 \mathrm{ug} / \mathrm{L}$; There were 11 phthalates detected during dry season. The content of Bis(2-methoxyethyl) phthalate was highest as $188.47 \mathrm{ng} / \mathrm{L} ; 17$ phenols were found in samples during wet season, and the highest concentration was $1244.73 \mathrm{ng} / \mathrm{L}$ for 4-nitrophenol; PAHs could be detected in all samples, and the detected compounds and the corresponding average concentrations were higher in wet seasons than those in dry seasons, which indicated that non-point pollution was possibly the main pollution source. The health risk assessment of the detected 56 pollutants by using a model from US EPA showed that, the risk caused by the four kinds of toxic organics in this study was in the acceptable ranges.
\end{abstract}


Keywords: Beijing; surface water; organic pollution; health risk assessment

\section{Introduction}

There are many potential toxic organics in surface water, and the organic matters with tritoxic and endocrine disrupting effects have a longer-lasting and latent impact on human health, which are priority pollutants controlled by many countries. Based on the list of preferential pollutants controlled in China and the previous studies on the characteristics of surface water in Beijing ${ }^{[1-5]}$, four major types of potential toxic organics were selected and researched, including: 15 phthalates (PAEs), 43 volatile organic compounds (VOCs, including halohydrocarbon, benzenes and chlorinated benzenes), 16 polycyclic aromatic hydrocarbons (PAHs) and 18 phenols. The contents and distribution characteristics of four types of pollutants those potential toxic organics were systematically investigated for the content of these four pollutants in major surface waters in Beijing. And distribution characteristics, and cancer risk and noncarcinogenic health risk assessment of some risk substances, in order to have a comprehensive understanding of the health risk level of surface water potential substances in Beijing, and provide scientific support for risk decision management.

\section{Experimental}

\subsection{Collection and preservation of water samples}

There were 7 sampling points in total, and the collection points were Xinzhuang Bridge, Daguan Bridge, Dongyingzi Village, Shichang Village, Tuancheng Lake, Daning Reservoir and Guanting, respectively. Moreover, sampling was conducted twice during the wet season (early July) and dry season (mid-October). The specific sampling point position was shown in Figure 1. Simultaneously, The Technical Specifications for Surface Water and Wastewater Monitoring (HJ/T91-2002) was strictly observed during the water sample collection process. Then samples were immediately placed in a portable freezer and shipped back to the laboratory for sample processing.

\subsection{Analysis method}

The PAEs samples were pretreated by liquid-liquid extraction using N-hexane and analyzed by GC/MSD. PAHs samples were pretreated by liquid-liquid extraction using dichloromethane and analyzed by GC/MSD. Phenols samples were pretreated by liquid-liquid extraction using dichloromethane, were finally analyzed by GC/MSD after derivatization by BSTFA. The sample analysis was conducted by Agilent 68905973 GC/MSD (Agilent, USA) with a DB-5MS capillary column $(30 \mathrm{~m} \times 0.25 \mathrm{~mm} \times 0.25 \mu \mathrm{m})$. The procedures in "Waters and wastewater monitoring 
analysis method Phthalate Ester and Hexanediol Gas Chromatography-Mass Spectrometry", "Waters and wastewater monitoring analysis method Polycyclic aromatic hydrocarbons Gas Chromatography-Mass Spectrometry" and "Waters and wastewater monitoring analysis method Phenol Gas Chromatography-Mass Spectrometry" were adopted ${ }^{[6]}$. VOCs sample analyzed by purge-trap GC/MSD according to the standard water quality methods ${ }^{[7]}$.

\subsection{Health risk assessment}

The health risk assessment model recommended by US EPA was adopted, which has been applied to the health risk assessment of human body by organic or inorganic pollutants in various environmental media ${ }^{[8-10]}$. The model was divided into carcinogenic and non-carcinogenic risk assessment. Inevitably, carcinogenic pollutants were non-carcinogenic to human body as well. Therefore, carcinogens should be evaluated not only for carcinogenic risk, but for non-carcinogenic risk.

$$
\begin{gathered}
\text { Risk }=\text { CDI } \times \text { SF, Risk }<0.01 \\
\text { Risk }=1-e^{(-\mathrm{CDI} \times \mathrm{SF})}, \text { Risk } \geq 0.01
\end{gathered}
$$

Carcinogenic Risk was usually expressed in terms of Risk value (Risk), which referred to the incidence of cancer caused by exposure to carcinogens beyond the normal level in a person's lifetime. It can be calculated by the following formula:

$$
\begin{gathered}
\text { Risk }=\text { CDI } \times \text { SF, Risk }<0.01 \\
\text { Risk }=1-e^{(-\mathrm{CDI} \times \mathrm{SF})}, \text { Risk } \geq 0.01
\end{gathered}
$$

CDI is the daily exposure value of human body, $\mathrm{mg} /(\mathrm{kg} \cdot \mathrm{d})$. And SF is the carcinogenic slope factor of pollutants, $(\mathrm{kg} \cdot \mathrm{d}) / \mathrm{mg}$. The acceptable cancer risk index recommended by US EPA is $10^{-6}-10^{-4}$.

Non-carcinogenic risks were generally expressed in terms of risk index (HI) with the following formula:

$$
\mathrm{HI}=\frac{C D I}{R f D}
$$

RfD represents the non-carcinogenic reference dose of the contaminant, $\mathrm{mg} /(\mathrm{kg} \cdot \mathrm{d})$. It is considered to be harmful to human health, when HI exceeds 1 .

Human exposure to organic pollutants in water included direct drinking and skin contact. As the risk value brought by skin contact was far less than that caused by drinking water ${ }^{[11]}$, only the risk by drinking water was considered in this paper.

The formula to calculate CDI for drinking water exposure was:

$$
\mathrm{CDI}=\frac{\mathrm{C} \times \mathrm{IR} \times \mathrm{EF} \times \mathrm{ED}}{\mathrm{BW} \times \mathrm{AT}}
$$

$\mathrm{C}$ is the concentration of pollutants in water, $\mathrm{mg} / \mathrm{L}$. IR is daily drinking water, $\mathrm{L} / \mathrm{d}$. $\mathrm{EF}$ is the exposure frequency, d/a. ED is exposure delay, a. BW stands for average weight, $\mathrm{kg}$. And AT represents the average exposure time, $\mathrm{d}$.

The value of parameters in the evaluation process was determined by the recommendation of US EPA. Thereinto, IR was $2 \mathrm{~L} / \mathrm{d}$ and EF was 365 d/a. ED was 30 
a for the non-carcinogen and 70 a for the carcinogen. Meanwhile, the average weight was revised as $61.8 \mathrm{~kg}$ according to Chinese official statistics ${ }^{[12]}$. For non-carcinogenic and carcinogenic substances, AT was set 10950 d (i.e., 30a) and 25550 d (i.e., 70 a), respectively. SF and RfD of various substances in the calculation were completely obtained from the US EPA database ${ }^{[13]}$.

\section{Results and Discussion}

\subsection{Analysis of pollution status of organic matter in surface water}

\subsection{1 status of pollution}

Most of the VOCs with carcinogenic, teratogenic, mutagenic, are bioaccumulative and difficult to degrade. In addition, they could be enriched through the food chain. PAEs are the most common global pollutants and endocrine disruptors, which seriously affect human health. Phenolic compounds of widely available are common organic pollutants in water. PAHs are persistent organic pollutants that can exist in the environment for a long time. In this study, the results of the detection of organic matter in the main surface water of Beijing were shown in Figure 2.

Only 11 kinds of total 43 VOCs were detected, and their overall concentration was below 10ug/L (Figure 2a), which was far less than the relevant provisions in the Environmental Quality Standard for Surface Water (GB3838-2002). During the wet season, there were 8 kinds of VOCs detected. The main pollutants in the dry season were detected as three kinds of chlorobenzenes, namely 1,3-dichlorobenzene, 1,4dichlorobenzene and 4-chlorotoluene, of which the concentrations were low (0.20$0.21 \mathrm{ug} / \mathrm{L}$ ), whereas the detection frequency was $100 \%$.

Phthalate organic substances, totally of 15 kinds, were detected (Figure 2b) 4 and 11 kinds in dry season and wet season, respectively. The detection frequencies of diisobutyl phthalate and din-butyl phthalate, two kinds of most commonly used plasticizers, were $100 \%$ in both wet and dry seasons, with a wide range of detection. While the concentration of diphenyl phthalate (2-methoxyethyl) in dry season was 16 times higher than that in wet season, of which the highest was $188.47 \mathrm{ng} / \mathrm{L}$. Ultimately, all the detected concentrations of phthalates were much smaller than the limits in the Surface Water Environmental Quality Standard (GB3838-2002).

A large number of phenolic compounds were detected at 7 sampling points (Figure 2c), among which 17 phenolic compounds were detected in wet season and 14 phenolic compounds were detected in dry season. Except for 2-methylphenol, the concentration of other substances was significantly higher in wet season than in dry season.

The detection frequencies of 16 PAHs in 7 surface waters were relatively high (Figure 2d), among which fluoranthene was the highest, followed by pyrene. In the 7 surface water samples, the detection frequencies of 16 PAHs were relatively high, among which fluoranthene was the highest, followed by pyrene. According to the 
sampling point statistics (data not shown), the least species of PAHs in dry season (only 2 kinds) were detected in Daguan Bridge, while all 16 kinds of PAHs were detected in Huairou and Baihe Dam in either wet or dry season. In consequence, PAHs pollution is common in surface water. Besides, the detection frequencies of phenanthrene and fluorene were higher, and the average detection concentration $(39.53 \mathrm{ng} / \mathrm{L}, 119.98 \mathrm{ng} / \mathrm{L})$ in wet season was significantly higher than that in dry season $(21.85 \mathrm{ng} / \mathrm{L}, 84.01 \mathrm{ng} / \mathrm{L})$.

\subsubsection{Analysis of pollution status}

The types of pollutants detected during the wet season and the dry season were different. The possible reason was that the organic matter detected during the wet period came from non-point source pollution. The high detection rate of pollutants in dry season indicated that these volatile organic compounds have been used in large quantities near rivers. In $2007^{[14]} 33$ volatile organic compounds $(11.47-25.27 \mathrm{ug} / \mathrm{L})$ were detected in Guanting Reservoir, and in $2012^{[1]} 43$ organic substances $(0-8.17 \mathrm{ug} / \mathrm{L})$ were detected. Compared with the results of this study, the types of VOCs detected in the main surface water in Beijing decreased significantly, while the concentration of VOCs decreased steadily.

The detection of phthalates in surface water has always been highly concerned by environmental researchers. In the $1980 \mathrm{~s}$, Zhao ${ }^{[15]}$ had discovered din-butyl phthalate (11.7-25.1ug/L) in Huairou Reservoir, Guanting Reservoir and Miyun Reservoir. Lin ${ }^{[16]}$ found that there were contaminations of di-n-butyl phthalate $(3.14-51.19 \mathrm{ug} / \mathrm{L})$ and butyl phthalate (4.08-7.98ug/L) in Miyun Reservoir and the upper reaches of Jingmi Water Diversion Canal in 2002. In 2017, di-n-butyl phthalate $(0.19-0.89 \mathrm{ug} / \mathrm{L})$ and bis(2-ethylhexyl) phthalate $(0.27-0.43 \mathrm{ug} / \mathrm{L})$ were detected in the upper reaches of Chaobai River ${ }^{[17]}$. The pollution concentration of phthalate esters measured in this study was all in ng/L level, with the highest value of $0.19 \mathrm{ug} / \mathrm{L}$ merely.

Among 7 sampling points, the 16 phenolic substances with concentrations ranging from $189.0 \mathrm{ng} / \mathrm{L}$ to $738.41 \mathrm{ng} / \mathrm{L}$ were detected at the sampling points of Tuancheng Lake. And their average concentration was far higher than that of other sampling points, while corresponding species and concentration detected in Daning Reservoir are far lower than Tuancheng Lake. Therefore, the prevention and control of non-point source pollution around Tuancheng Lake should be paid special attention. In addition, although the detection frequency of 4-nitrophenol was low, the detected concentration was high, varying in order of $169.94 \mathrm{ng} / \mathrm{L}, 360.79 \mathrm{ng} / \mathrm{L}$ and $1244.73 \mathrm{ng} / \mathrm{L}$, which also needed to be paid attention.

As a special and stable ring-shaped pollutant, polycyclic aromatic hydrocarbons, which persists in surface water as a water supply source, should be given sufficient attention by relevant departments. The ratio of the isomers of PAHs in the water can indicate its source and thus be controlled in a targeted manner. According to the research of Yunker et al. ${ }^{[18]}$ and the test results of this study, it could be seen that 
the PAHs in Beijing surface water mainly originate from the combustion of coal, and the petroleum source is less.

\subsection{Health risk assessment of organic compounds in surface water}

There were only 10 of 56 kinds of detected organic substances that were controlled by the Surface Water Environmental Quality Standard. Many pollutants still lack standard controls. The health risk assessment results of detected organics were shown in Table 2. The results showed that: the carcinogenic risk of phthalates, PAHs, phenols and VOCs increased successively. The carcinogenic risk of the other three types of substances was about an order of magnitude higher in wet season than dry season, except for the phthalate lipid pollutants, which showed again that non-point source pollution was an important factor affecting water quality. The carcinogenic risk of various pollutants was within the acceptable risk range recommended by US EPA $\left(10^{-6}-10^{-4}\right)$. The types and concentrations of VOCs detected were not high, while the carcinogenic risk was the highest. Among 92 pollutants, chloroform and 1,2dichloroethane were the two pollutants with the highest carcinogenic risk. Therefore, the control of VOCs needs special concern. 3) The range of non-carcinogenic risk was $8.84 \times 10^{-5}-4.63 \times 10^{-2}$, which was far less than 1 , within the safe range.

Since only half of the carcinogenic slope factors or non-carcinogenic reference doses of organic compounds were available (28 species), and the harm caused by drinking water to human health was calculated in this paper simply without considering the skin contact route. Actually, the health risks of toxic pollutants in the water environment were underestimated. In addition, some low-carcinogenic organic pollutants, such as phthalates, had more significant endocrine effects, of which ecological risk assessment should be carried out to reflect the harm of these pollutants in the water environment comprehensively.

\section{Conclusion}

56 toxic organic pollutants, including 11 VOCs, 11 phthalates, 18 phenols and 16 PAHs, were detected in main surface water of Beijing. The detection frequencies and concentrations of phthalates and VOCs were low, while phenolic compounds and PAHs were detected with higher species, detection frequencies and concentrations. The detection frequencies and concentrations of the other three types of pollutants were basically higher in wet season than dry season, except for phthalates. Therefore, the prevention and control of non-point source pollution should be strengthened in Beijing.

Among 56 substances detected, carcinogenic risk assessment was conducted for 10 pollutants with basic toxicity data, and non-carcinogenic risk assessment was evaluated with 26 pollutants. The evaluation results indicated that the risk of organic compounds in the surface water of Beijing to human health was at an acceptable level. 
Acknowledgements: The authors would like to thank the research and demonstration of total amount control of water environmental pollution and control technologies and management systems of livestock and poultry pollution in the Northern Canal Basin (Beijing section) for their support in carrying out this research.

\section{References}

1. Chen XC, Luo Q, Song HW, et al (2013) Screening of priority contaminants and health risk assessment in Beijing Guanting reservoir. Asian Journal of Ecotoxicology 6:981-992. http://doi.org/10.7524/AJE.1673-5897.20130307002

2. Li X, Wang DH, Wang JS, et al (2015) Analysis of persistent organic pollutants (POPs) levels in dry and wet seasons in source water of municipal waterworks in Beijing. Acta Scientiae Circumstantiae 35(2):437-442.

http://doi.org/10.13671/j.hjkxxb.2014.0813

3. Wang YF, Ren SJ, Li MR et al (2015) Residue characteristics and health risks of Polycyclic Aromatic Hydrocarbons in Guanting Reservoir. Journal of Beijing Normal University (Natural Science) 1:60-63. http://doi.org/10.16360/j.cnki.jbnuns.2015.01.014

4. Li JD (2015). The Pollution Characteristics and Chiral Signatures of Typical Persistent Organic Environmental Pollutants in the Environment and Food from the Beijing Area. China Agricultural University.

5. Peng CW (2017) Characteristics and risk evaluation of environmental endocrine in groundwater in Beijing. Chinese Academy of Sciences.

6. Wei FS, et al (2002) State Environmental Protection Administration. Waters and wastewater monitoring analysis method, 4th ed. China Environmental Science Press, Beijing, p562.

7. MEPC-Ministry of Environmental Protection of China (2012) Water quality Determination of volatile organic compounds -Purge and trap/gas chromatography-mass spectrometer, HJ 639-2012, Beijing, 1-24.

8. Geng MJ, Chang S, Liu Y et al. (2016) Pollution status and health risks of drinking water of the polycyclic aromatic hydrocarbons and phthalate esters in the deep shallow pore water of Hutuo River Pluvial Fan. China Environmental Science 12:3824-3830. http://qikan.cqvip.com/Qikan/Article/Detail?id=7000082560

9. Zhu Y, Tao S, Sun JT et al. (2019) Multimedia modeling of the PAH concentration and distribution in the Yangtze River Delta and human health risk assessment. SCIENCE OF THE TOTAL ENVIRONMENT. 647:962-972. http://doi.org/10.1016/j.scitotenv.2018.08.075

10. Rahman MS, Khan MDH, Jolly YN et al. (2019) Assessing risk to human health for heavy metal contamination through street dust in the Southeast Asian 
Megacity: Dhaka, Bangladesh. SCIENCE OF THE TOTAL ENVIRONMENT 660:1610-1622. http://doi.org/10.1016/j.scitotenv.2018.12.425

11. He T, Xu ZC, Wei DY et al. (2014) Environmental Health Risk Assessment of Phthalic Acid Esters Like Pollutants in Reservoir or Lake Type Water; Source Catchments in the Pearl River Basin. Rural Eco-Environment 6:699-705. http://qikan.cqvip.com/Qikan/Article/Detail?id=663756677

12. MOH (2015) Report on Nutrition and Chronic Diseases of Chinese Residents. National Health Commission of the People's Republic of China. http://www.moh.gov.cn/zhuz/spaqyyy/201506/4505528e65f3460fb88685081ff15 8a2.shtml

13. NCEA (2015) Integrated Risk Information System. US EPA. https://cfpub.epa.gov/ncea/iris_drafts/simple_list.cfm

14. Cheng LJ (2008) Analysis and Evaluation of Water Quality of Surface Water Sources in Beijing. Beijing University of Chemical Technology.

15. Zhao ZH (1986) Phthalic acid esters research in environment of China. Chinese Journal of Environmental Engineering 5: 50-57.

16. Lin XT (2003) Phthalic acid esters research in the water of Beijing. Beijing University of Technology.

17. Liu ST, Wang HB, Zheng QG (2017) Determination of 6 phthalic acid esters in the water of in Shunyi section of Chaobai River and Hanshiqiao wetland of Beijing. Chinses Journal of Health Laboratory Technology 8:1095-1097+1100. http://qikan.cqvip.com/Qikan/Article/Detail?id=672039746

18. Yunker MB, Macdonald RW, Vingarzan R et al. (2002) PAHs in the Fraser River basin: a critical appraisal of PAHs rations as indicators of PAH source and composition. Organic Geochemistry 33:489-515.http://doi.org/10.1016/S0146$\underline{6380(02) 00002-5}$ 


\section{List of Tables}

Table1. Source indicated by the ratios of PAHs isomers

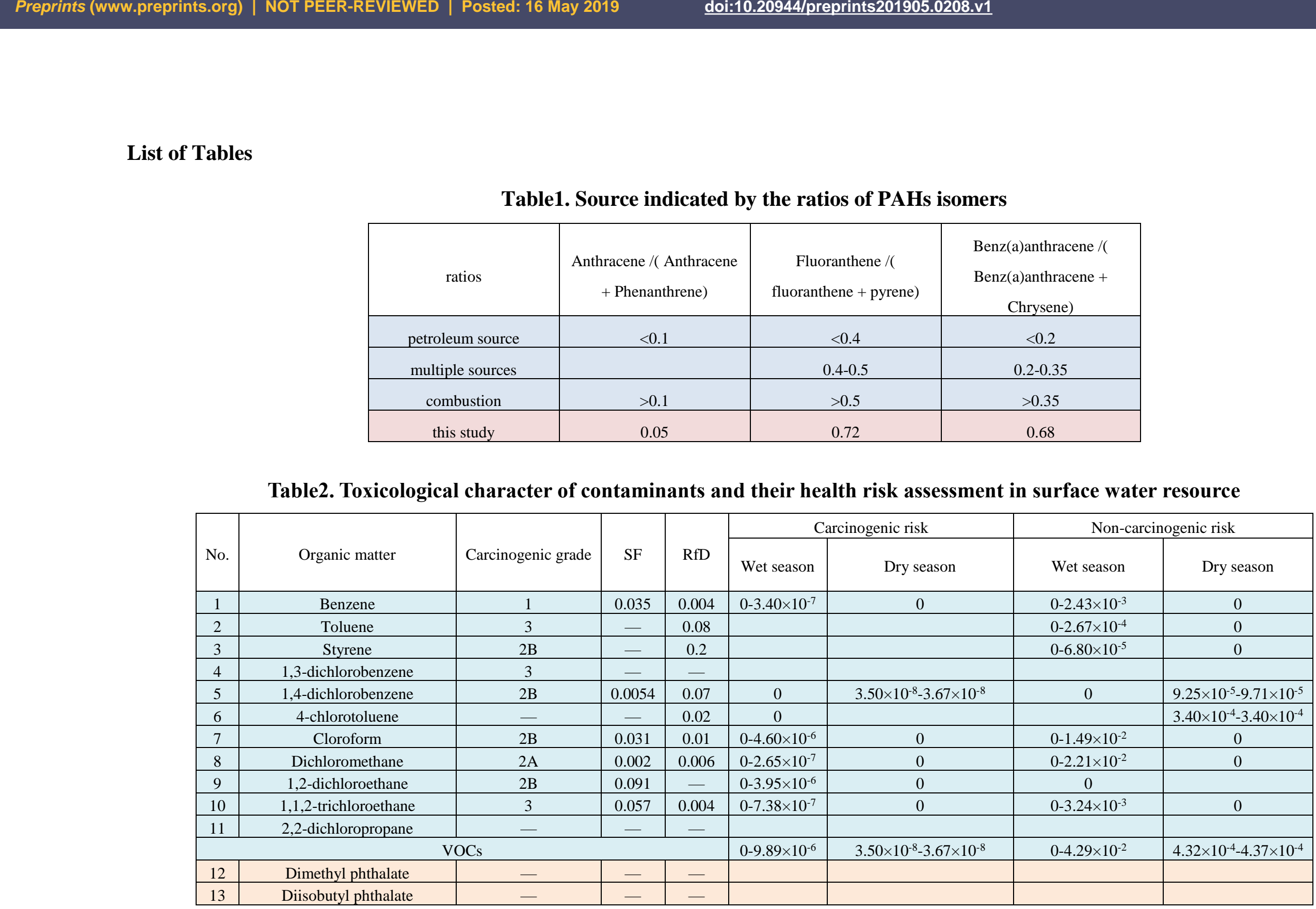

Table2. Toxicological character of contaminants and their health risk assessment in surface water resource






\begin{tabular}{|c|c|c|c|c|c|c|c|c|}
\hline 14 & Di-n-butyl phthalate & - & - & 0.1 & & & $2.89 \times 10^{-6}-6.78 \times 10^{-6}$ & $2.15 \times 10^{-6}-4.38 \times 10^{-6}$ \\
\hline 15 & Bis(2-methoxyethyl) phthalate & - & - & - & & & & \\
\hline 16 & Diethoxyethyl phthalate & - & - & - & & & & \\
\hline 17 & Dipentyl phthalate & - & - & - & & & & \\
\hline 18 & Butyl benzyl phthalate & - & - & 0.2 & & & 0 & $0-1.13 \times 10^{-6}$ \\
\hline 19 & Di(2-butoxy)ethyl phthalate & - & - & - & & & & \\
\hline 20 & Dicyclohexyl phthalate & - & - & - & & & & \\
\hline 21 & Dioctyl phthalate & $2 \mathrm{~B}$ & 0.014 & 0.02 & 0 & $0-3.07 \times 10^{-9}$ & 0 & $0-1.10 \times 10^{-5}$ \\
\hline 22 & Didecyl phthalate & - & - & - & & & & \\
\hline \multicolumn{5}{|c|}{ Phthalates } & 0 & $0-3.07 \times 10^{-9}$ & $2.89 \times 10^{-6}-6.78 \times 10^{-6}$ & $2.15 \times 10^{-6}-1.65 \times 10^{-5}$ \\
\hline 23 & Phenol & 3 & - & 0.3 & & & $0-2.04 \times 10^{-5}$ & $0-8.72 \times 10^{-7}$ \\
\hline 24 & 2-methylphenol & - & - & 0.05 & & & 0 & $0-1.77 \times 10^{-6}$ \\
\hline 25 & 3-methylphenol & - & - & 0.05 & & & $2.28 \times 10^{-6}-1.56 \times 10^{-4}$ & $0-7.74 \times 10^{-6}$ \\
\hline 26 & 4-methylphenol & - & - & - & & & & \\
\hline 27 & 4-ethylphenol & - & - & - & & & & \\
\hline 28 & 2-nitrophenol & - & - & - & & & & \\
\hline 29 & 4-nitrophenol & - & - & - & & & & \\
\hline 30 & 2-chlorophenol & - & - & - & & & & \\
\hline 31 & 2,4-dichlorophenol & - & - & 0.03 & & & $0-2.65 \times 10^{-4}$ & 0 \\
\hline 32 & 2,6-dichlorophenol & - & - & - & & & & \\
\hline 33 & 2,4,5-trichlorophenol & - & - & 0.01 & & & $0-8.28 \times 10^{-4}$ & $0-6.68 \times 10^{-5}$ \\
\hline 34 & 2,4,6-trichlorophenol & $2 \mathrm{~B}$ & 0.011 & - & $0-1.08 \times 10^{-7}$ & 0 & & \\
\hline 35 & 2,3,4,6-tetrachlorophenol & - & - & 0.03 & & & $0-3.33 \times 10^{-4}$ & $0-2.54 \times 10^{-5}$ \\
\hline 36 & Pentachlorophenol & 1 & 0.4 & 0.005 & $0-1.54 \times 10^{-6}$ & $0-1.32 \times 10^{-7}$ & $0-7.72 \times 10^{-4}$ & $0-6.62 \times 10^{-5}$ \\
\hline 37 & 4-chloro-3-methylphenol & - & - & - & & & & \\
\hline 38 & O-phenylphenol & 3 & - & - & & & & \\
\hline 39 & Bisphenol A & - & - & 0.05 & & & $5.31 \times 10^{-5}-4.78 \times 10^{-4}$ & $3.42 \times 10^{-6}-3.61 \times 10^{-4}$ \\
\hline 40 & Nonylphenol & - & - & - & & & & \\
\hline \multicolumn{5}{|c|}{ Phenols } & $0-1.65 \times 10^{-6}$ & $0-1.32 \times 10^{-7}$ & $5.54 \times 10^{-5}-2.85 \times 10^{-3}$ & $3.42 \times 10^{-6}-5.30 \times 10^{-4}$ \\
\hline 41 & Naphthalene & $2 \mathrm{~B}$ & - & 0.02 & & & $0-1.96 \times 10^{-5}$ & $0-9.69 \times 10^{-5}$ \\
\hline 42 & Terpene & - & - & - & & & & \\
\hline 43 & Acenaphthene & 3 & - & 0.06 & & & $8.40 \times 10^{-7}-1.54 \times 10^{-5}$ & $0-1.07 \times 10^{-5}$ \\
\hline 44 & Fluorene & 3 & - & 0.04 & & & $1.66 \times 10^{-5}-7.03 \times 10^{-5}$ & $0-6.69 \times 10^{-5}$ \\
\hline 45 & Phenanthrene & 3 & - & - & & & & \\
\hline 46 & Anthracene & 3 & - & 0.3 & & & $2.44 \times 10^{-7}-1.64 \times 10^{-6}$ & $0-9.99 \times 10^{-7}$ \\
\hline
\end{tabular}




\begin{tabular}{|c|c|c|c|c|c|c|c|c|}
\hline 47 & Fluoranthene & 3 & - & 0.04 & & & $5.02 \times 10^{-6}-1.35 \times 10^{-5}$ & $3.80 \times 10^{-7}-3.30 \times 10^{-5}$ \\
\hline 48 & Pyrene & 3 & - & 0.03 & & & $3.84 \times 10^{-6}-1.42 \times 10^{-5}$ & $0-2.30 \times 10^{-5}$ \\
\hline 49 & Benz(a)anthracene & $2 \mathrm{~B}$ & - & - & & & & \\
\hline 50 & Chrysene & - & - & - & & & & \\
\hline 51 & Benzo[b]fluorathene & $2 \mathrm{~B}$ & - & - & & & & \\
\hline 52 & Benzo[k]fluoranthene & $2 \mathrm{~B}$ & - & - & & & & \\
\hline 53 & Benzo[a]pyrene & 1 & 1 & 0.0003 & $0-1.23 \times 10^{-7}$ & $0-4.88 \times 10^{-8}$ & $0-4.11 \times 10^{-4}$ & $0-1.63 \times 10^{-4}$ \\
\hline 54 & Dibenz[a,h] anthracene & $2 \mathrm{~A}$ & - & - & & & & \\
\hline 55 & Indeno[ $[1,2,3$-cd $]$ Pyrene & $2 \mathrm{~B}$ & - & - & & & & \\
\hline 56 & Benzo[g,h,i]perylene & 3 & - & - & & & & \\
\hline \multicolumn{5}{|c|}{$\mathrm{Hs}$} & $0-1.23 \times 10^{-7}$ & $0-4.88 \times 10^{-8}$ & $2.65 \times 10^{-5}-5.45 \times 10^{-4}$ & $3.80 \times 10^{-7}-3.94 \times 10^{-4}$ \\
\hline & Total & & & & $0-1.17 \times 10^{-5}$ & $3.68 \times 10^{-8}-2.21 \times 10^{-}$ & $\left|8.48 \times 10^{-5}-4.63 \times 10^{-2}\right|$ & $4.45 \times 10^{-4}-1.38 \times 10^{-3}$ \\
\hline
\end{tabular}




\section{List of Figures}



Fig1. Sampling sites in the surface water of Beijing

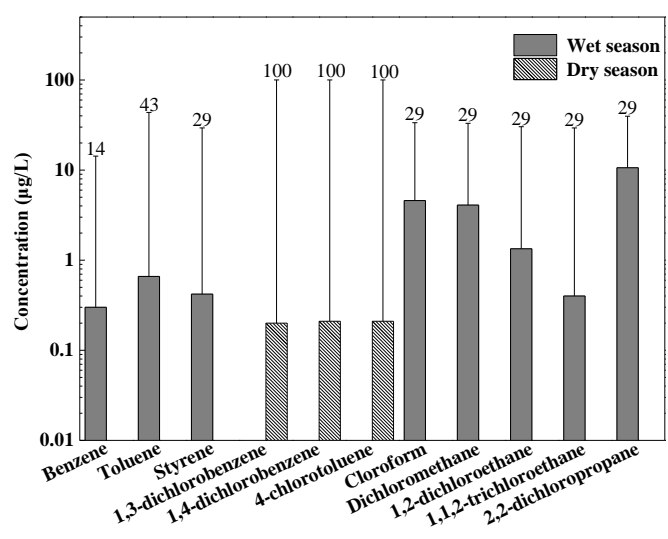

a VOCs

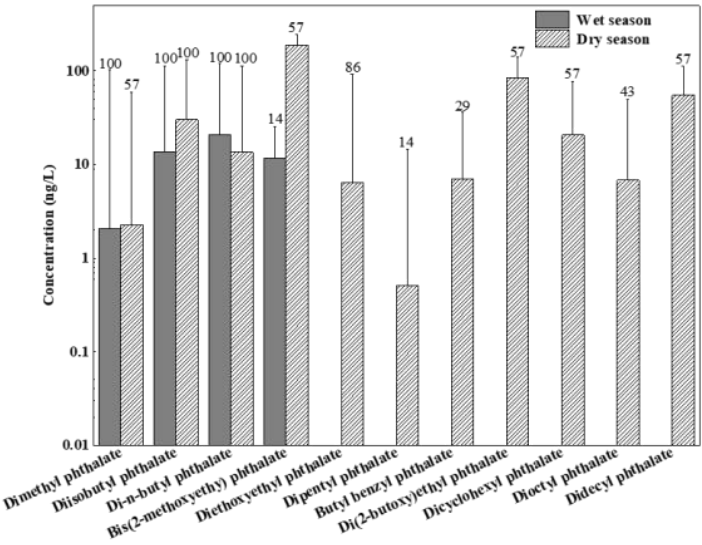

b PAEs 


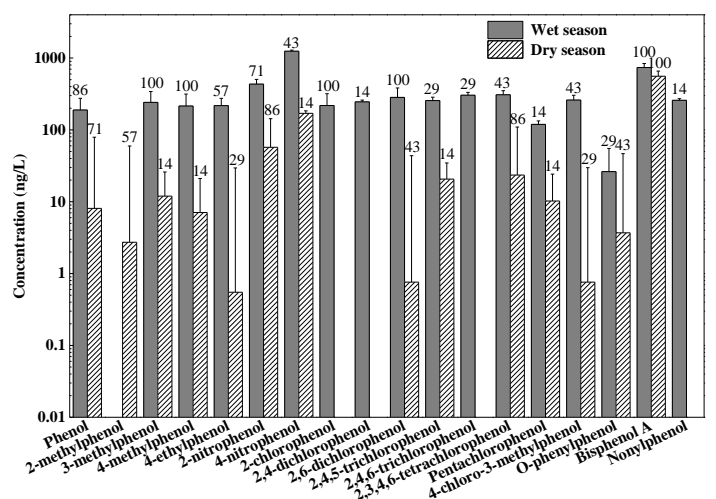

c Phenols

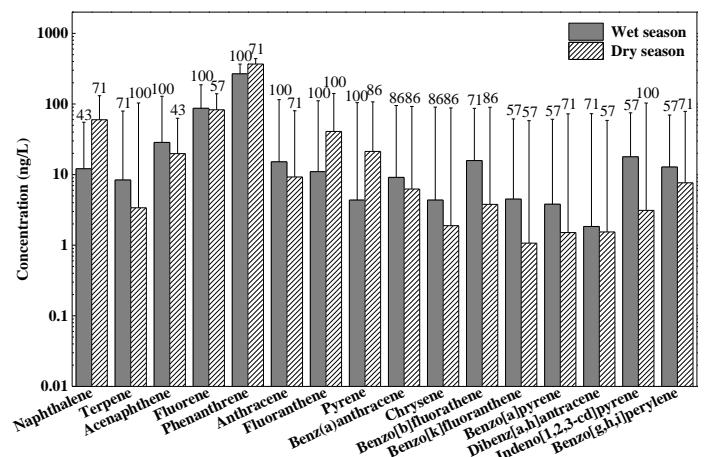

d PAHs

Fig2. Concentrations and detection frequencies of organics in surface water of Beijing. The box and whisker represent the median value and the maximum detected concentration, respectively, and the detection frequency $(\%)$ of each organic is indicated at the top. 